\title{
PENGARUH pH MEDIUM TERHADAP DISOLUSI IBUPROFEN DENGAN METODE DISPERSI PADAT
}

\author{
Uswatun Hasanah ${ }^{1, *}$, Mirhansyah Ardana ${ }^{1}$, Rolan Rusli ${ }^{1,2, \dagger}$ \\ ${ }^{1}$ Laboratorium Penelitian dan Pengembangan Kefarmasian "Farmaka Tropis", \\ Fakultas Farmasi, Universitas Mulawarman, Samarinda \\ *Email : uas.hasanah@gmail.com \\ ${ }^{2}$ Program Studi Pendidikan Kimia, Fakultas Keguruan dan Ilmu Pendidikan, \\ Universitas Mulawarman, Samarinda \\ tEmail: rolan@farmasi.unmul.ac.id
}

\begin{abstract}
Bioavailability of the drug is a parameter that can demonstrate the effectiveness of a pharmaceutical products. Dissolution rate is a factor that can affect the bioavailability. One of the methods can be used to improve the dissolution rate of poorly soluble compounds in water as ibuprofen is the formation of a solid dispersion with a polymer that can improve the solubility in water, for example, PVP (polyvinyl pyrrolidone) K30. The purpose of this study was to determine the effect of solid dispersion in increasing the dissolution rate of ibuprofen in $\mathrm{HCl} \mathrm{pH}$ 1.2 and pH 6.8 phosphate buffer. The research carried out by making solid dispersions of ibuprofen-PVP K30 at a ratio of $1: 9$ using dissolution method, and then tested using a apparatus type II, at the paddle rotation speed of $50 \mathrm{rpm}$, temperature of $37 \pm 0.5^{\circ} \mathrm{C}$ for 120 minutes. The results showed that the formation of the solid dispersion can improve the both the rate of dissolution at $\mathrm{pH} 1.2$ and 6.8 .
\end{abstract}

Key Words: Dissolution, solid dispersion, pH, Ibuprofen, polyvinyl pyrrolidone.

\begin{abstract}
ABSTRAK
Bioavaibilitas obat merupakan parameter yang dapat menunjukan efektifitas suatu sediaan farmasi. Laju disolusi merupakan faktor yang dapat mempengaruhi bioavaibilitas. Salah satu metode yang dapat digunakan untuk meningkatkan laju disolusi dari senyawa yang sukar larut dalam air seperti ibuprofen adalah dengan pembentukan dispersi padat dengan polimer yang dapat meningkatkan kelarutan dalam air, misalnya PVP (polyvinyl pirrolidone) K30. Tujuan penelitian ini adalah untuk mengetahui pengaruh dispersi padat dalam meningkatkan disolusi ibuprofen pada medium $\mathrm{HCl} \mathrm{pH}$ 1,2 dan dapar fosfat $\mathrm{pH}$ 6,8. Penelitian dilakukan dengan
\end{abstract}


membuat dispersi padat ibuprofen-PVP K30 pada perbandingan 1 : 9 dengan metode pelarutan, lalu diuji disolusi menggunakan apparatus tipe II, kecepatan 50 rpm, suhu $37 \pm 0,5^{\circ} \mathrm{C}$ selama 120 menit. Hasil menunjukkan bahwa pembentukan disperse padat dapat meningkatkan laju disolusi baik pada $\mathrm{pH} 1,2$ maupun pada $\mathrm{pH}$ 6,8 .

Kata Kunci: $\quad$ Disolusi, Dispersi Padat, pH, Ibuprofen, polyvinyl pyrrolidone.

\section{PENDAHULUAN}

Sistem Klasifikasi Biofarmasetika (Bhiopharmaceutics Classification System atau BCS) merupakan sistem klasifikasi bahan aktif obat berdasarkan dua faktor penting yaitu kelarutan dan permeabilitasnya. Berdasarkan klasifikasi obatobat kelas II merupakan obat-obat yang sulit diabsorpsi secara sempurna karena memiliki kelarutan dan kecepatan disolusi yang terlalu rendah walaupun sangat permeabel terhadap membran [1]. Sehingga pengujian disolusi paling baik dilakukan untuk obat-obat kelas II karena memiliki kecepatan disolusi yang rendah, sedangkan kecepatan disolusi merupakan karakteristik penentu utama absorpsi [2]. Salah satu metode untuk meningkatkan kecepatan disolusi adalah dengan sistem dispersi padat.

Dispersi padat adalah campuran yang homogen dari satu atau lebih bahan aktif dalam matriks yang inert dengan tujuan untuk meningkatkan bioavalibilitas oral dari bahan obat yang sukar larut. Teknologi ini dapat memperkecil ukuran partikel bahan obat dengan membentuk suatu campuran eutektik dari bahan obat yang sukar larut dengan pembawa yang mudah larut dalam air, sehingga dapat meningkatkan kelarutan serta absorpsi bahan obat [3]. Pembawa yang sering digunakan dalam pembuatan dispersi padat adalah Polyvinylpyrrolidone (PVP).

Polyvinylpyrrolidone (PVP) merupakan salah satu bahan yang sering digunakan untuk membentuk suatu sistem dispersi padat dengan beberapa zat aktif [4]. Akan tetapi penelitian untuk melihat peningkatan disolusi ibuprofen dengan metode dispersi padat hanya dilakukan pada satu jenis medium pada $\mathrm{pH}$ tertentu saja. Oleh karena itu dilakukanlah penelitian ini guna membandingkan peningkatan laju disolusi ibuprofen dengan metode dispersi padat pada $\mathrm{pH}$ medium yang berbeda, yaitu $\mathrm{pH} 1,2$ dan 6,8 .

\section{METODE PENELITIAN}

\section{Alat}

Alat uji disolusi (Copley), Spektrofotometer double beam (Dynamica, HALO DB-20S), pH meter (JENWAY 307), dan seperangkat alat-alat yang umum digunakan di laboratorium. 


\section{Bahan}

Ibuprofen, PVP (Polyvinyl pyrrolidone) K30, etanol $96 \%$, HCl $37 \%, \mathrm{NaCl}$ (Merck KGaA, Germany), $\mathrm{KH}_{2} \mathrm{PO}_{4}, \mathrm{NaOH}$ dan Air suling.

\section{Pembuatan Dispersi Padat}

Pembuatan dispersi pada menggunakan metode pelarutan [5], yaitu dengan melarutkan ibuprofen dan PVP K30 dengan perbandingan $1: 9$ dalam sejumlah etanol $96 \%$. Kemudian di stirrer sambil dipanaskan pada suhu $40{ }^{\circ} \mathrm{C}$ selama 1 jam. Disimpan pada suhu ruang selama 48 jam.

\section{Pembuatan Medium Disolusi}

Pembuatan medium dapar fosfat $\mathrm{pH}$ 6,8 seperti yang tertera pada Farmakope Indonesia Edisi IV [6]. Sedangkan pembuatan $\mathrm{HCl} \mathrm{pH} \mathrm{1,2} \mathrm{[7],} \mathrm{yaitu}$ sebanyak 2,0 g natrium klorida $\mathrm{P}$ dilarutkan dalam $7,0 \mathrm{ml} \mathrm{HCl} P$ dan air secukupnya hingga $1000 \mathrm{~mL}$. Larutan mempunyai $\mathrm{pH}$ lebih kurang 1,2.

\section{Pengujian Disolusi}

Pengujian dilakukan menggunakan apparatus II (paddle) dengan kecepatan pengadukan $50 \mathrm{rpm}$, dalam $500 \mathrm{~mL}$ medium, suhu $37 \pm 0,5{ }^{\circ} \mathrm{C}$, serta dilakukan pengujian selama 120 menit. Pada waktu tertentu dilakukan pengambilan sampel sebanyak $5 \mathrm{~mL}$ dan digantikan dengan medium baru dalam jumlah yang sama. Kemudian diukur absorbansi sampel menggunakan spektrofotometer pada $\lambda 222,2$ $\mathrm{nm}$ untuk medium dapar fosfat $\mathrm{pH} 6,8$ dan $\lambda 220,2 \mathrm{~nm}$ untuk medium $\mathrm{HCl} \mathrm{pH} \mathrm{1,2}$ [5].

\section{HASIL DAN PEMBAHASAN}

Pada penelitian ini, untuk menentukan kadar ibuprofen dalam sampel digunakan persamaan regresi linear dari kurva baku. Kurva baku ditentukan pada masing-masing medium karena $\mathrm{pH}$ dari medium akan mempengaruhi absorbansi dari ibuprofen. Kurva baku ibuprofen pada medium $\mathrm{HCl}$ pH 1,2 dan medium dapar fosfat $\mathrm{pH}$ 6,8 disajikan pada Gambar 1 . 


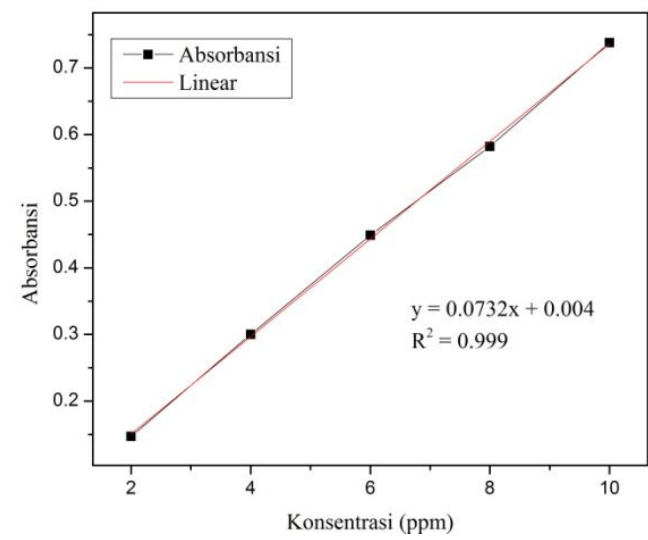

(a)

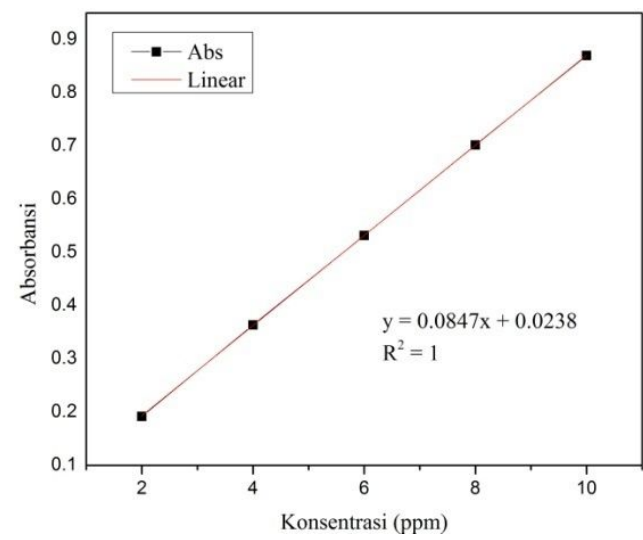

(b)

Gambar 1. Kurva baku ibuprofen pada (a) medium $\mathrm{HCl} \mathrm{pH} \mathrm{1,2} \mathrm{dan} \mathrm{(b)} \mathrm{medium}$ dapar fosfat $\mathrm{pH} 6,8$

Persamaan regresi linear yang diperoleh pada medium $\mathrm{HCl} \mathrm{pH} \mathrm{1,2} \mathrm{adalah}$ $y=0,0732 x+0,004$ dengan $R^{2}=0,999$. Sedangkan persamaan regresi linear yang diperoleh pada medium dapar fosfat $\mathrm{pH} 6,8$ adalah $\mathrm{y}=0,0847 \mathrm{x}+0,0238$ dengan $\mathrm{R}^{2}=1$. Persamaan regresi dengan nilai $\mathrm{R}$ yang semakin mendekati 1 maka semakin baik data tersebut digunakan, maka data yang diperoleh telah sesuai atau baik digunakan dalam penentuan konsentrasi.

Pengujian laju disolusi dilakukan dengan metode yang sesuai kemudian ditentukan $\%$ terdisolusi dan profil disolusinya. Hasil pengujian $\%$ terdisolusi ibuprofen dan disperse padat ibuprofen-PVP K30 pada seperti terlihat pada medium $\mathrm{HCl} \mathrm{pH}$ 1,2 dan medium dapar fosfat $\mathrm{pH}$ 6,8 seperti terlihat pada Gambar 2.

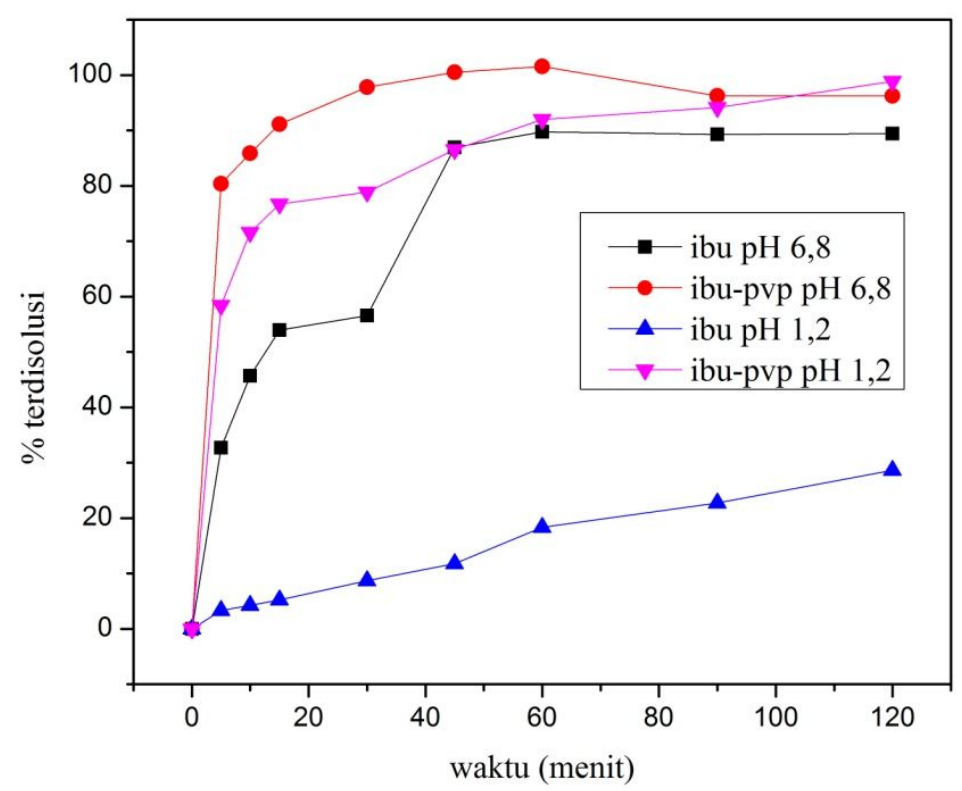


Gambar 2: Profil Disolusi Ibuprofen dan dispersi padat ibuprofen-PVP K30 pada medium $\mathrm{HCl} \mathrm{pH}$ 1,2 dan medium dapar fosfat $\mathrm{pH} 6,8$

Metode dispersi padat tampak dapat meningkatkan kecepatan disolusi ibuprofen baik pada medium $\mathrm{HCl} \mathrm{pH} \mathrm{1,2}$ maupun pada medium dapar fosfat $\mathrm{pH}$ 6,8. Pada medium $\mathrm{HCl} \mathrm{pH} 1,2$ terjadi peningkatan disolusi sebesar $55 \%$ antara ibuprofen dan dispersi padat ibuprofen-PVP K30 pada menit ke 5. Sedangkan antara ibuprofen dan dispersi padat ibuprofen-PVP K30 pada medium dapar fosfat pH 6,8 terjadi peningkatan sebesar 47,63\%. Sehingga terlihat peningkatan laju disolusi dispersi padat ibuprofen-PVP K30 pada medium $\mathrm{HCl} \mathrm{pH} \mathrm{1,2} \mathrm{terlihat} \mathrm{lebih}$ signifikan.

$\mathrm{pH}$ medium sangat mempengaruhi laju disolusi dari bahan-bahan yang bersifat asam atau basa. Untuk bahan yang bersifat asam, medium dengan $\mathrm{H}^{+}$kecil atau $\mathrm{pH}$ besar akan meningkatkan kelarutan bahan sehingga laju disolusi semakin cepat [8]. Hal tersebut dapat terlihat pada laju disolusi ibuprofen pada medium $\mathrm{HCl}$ $\mathrm{pH} 1,2$ dan medium dapar fosfat $\mathrm{pH}$ 6,8 memiliki perbedaan yaitu pada $\mathrm{pH} \mathrm{1,2}$ hanya terdisolusi $28,6 \%$ pada menit ke 120 . Sedangkan pada $\mathrm{pH} 6,8$ telah mencapai $32.7 \%$ pada menit ke 5 dan mencapai $89,4 \%$ pada menit ke 120 . pH medium

Ibuprofen merupakan senyawa yang bersifat asam dan berbentuk Kristal [1]. Dalam bentuk dispersi padat, PVP K30 membantu peningkatan kelarutan dari ibuprofen, karena ibuprofen yang berbentuk Kristal akan menjadi amorf. Setelah pelarut menguap, PVP akan mencegah terjadinya rekristralisasi ibuprofen dengan membentuk dispersi padat dimana ibuprofen terdispersi dalam PVP K30.

Selain terjadinya perubahan bentuk dari ibuprofen tersebut, PVP K30 sangat mudah larut dalam asam, dan beberapa pelarut organik lain [4]. Sehingga bentuk dispersi padat dengan PVP K30 dapat meningkatkan kelarutan dari ibuprofen medium $\mathrm{HCl}$ $\mathrm{pH} 1,2$ maupun pada medium dapar fosfat $\mathrm{pH} 6,8$.

\section{KESIMPULAN}

Pembuatan dispersi padat dengan menggunakan PVP K30 efektif dapat meningkatkan kecepatan disolusi dari ibuprofen baik pada medium dapar fosfat $\mathrm{pH}$ 6,8 maupun medium $\mathrm{HCl} \mathrm{pH}$ 1,2. Akan tetapi peningkatan laju disolusi dispersi padat ibuprofen-PVP K30 pada medium $\mathrm{HCl}$ pH 1,2 terlihat lebih signifikan.

\section{DAFTAR PUSTAKA}

[1] Sriraviteja, Nalla., dan Kodalipavan, Kumar. 2013. Effect of Application of Solubilizers Such as PVP K 30, PEG 400 and Tween 80 on The Enhancement of Solubility of Ibuprofen by Factorial Design. International Journal of Pharmaceutical Research and Bio-Science. 2 (5) 182-202

[2] Sinko, Patrick J. 2011. Martin Farmasi Fisika dan Ilmu Farmasetika. Penerbit Buku Kedokteran EGC: Jakarta. 
[3] Retnowati, Dini dan Dwi Setyawan. 2010. Peningkatan Disolusi Ibuprofen Dengan Sistem Dispersi Padat Ibuprofen-PVP K90. Majalah Farmasi Airlangga Volume 8 Nomor (1) halaman 1-6

[4] Rowe, R, C., Sheskey, P.J., dan Weller, P.J. 2009. Handbook of Pharmaceutical Excipients. Edisi VI. Publisher-Science and Practice Royal Pharmaceutical Society of Great Britain: London.

[5] Giri, Tapan Kumar dan Badwaik, Hemant. 2010. Solubility Enhancement Of Ibuprofen In The Presence Of Hydrophilic Polymer And Surfactant. International Journal Of Applied Biology And Pharmaceutical Technology Volume I Nomor (2) halaman 793-800

[6] Depkes RI. 1995. Farmakope Indonesia, ed. IV. Depkes RI: Jakarta.

[7] Hasyim, Nursiah, Mirawati, dan Sri Sulistiana. 2012. Pengembangan Formulasi Tablet Matriks Gastroretentive Floating Dari Amoksisilin Trihidrat. Majalah Farmasi dan Farmakologi, Volume 16 Nomor (3) halaman. 131-138

[8] Fudholi, Achmad. 2013. Disolusi Dan Pelepasan Obat In Vitro. Pustaka Pelajar: Yogyakarta. 